\title{
Tomographic Optical Breast Imaging
}

National Cancer Institute

\section{Source}

National Cancer Institute. Tomographic Optical Breast Imaging. NCI Thesaurus. Code C158498.

Diffuse optical breast imaging that utilizes near-infrared (NIR) light propagation through breast tissues to assess the optical properties of tissue for the identification of abnormalities. 